\title{
Lexical guidance in sentence processing?
}

\author{
BEVERLY COLWELL ADAMS \\ University of Virginia, Charlottesville, Virginia \\ CHARLES CLIFTON, JR. \\ University of Massachusetts, Amherst, Massachusetts \\ and \\ DON C. MITCHELL \\ University of Exeter, Exeter, England
}

\begin{abstract}
An eyetracking experiment was conducted to explore a self-paced reading effect reported by Mitchell (1987). Mitchell found that a noun phrase (NP) was read slowly when it immediately followed an intransitive verb, as long as the verb and NP appeared in the same presentation region. This effect has been used to support the claim that verb subcategorization information is not used initially in sentence parsing. However, the effect did not appear in the eyetracking experiment reported in the present paper, supporting criticisms that Mitchell's segmentation procedure distorted the parsing process.
\end{abstract}

Understanding a sentence involves, among many other factors, determining the syntactic relations among the words and phrases of a sentence. For instance, in After the dog scratched the veterinarian ..., a reader or listener must decide whether the noun phrase (NP) the veterinarian following the verb scratch is the direct object of that verb or whether it is the subject of a new clause. In this process of "parsing" a sentence, readers and listeners must obey the grammatical principles of their language, and they must also honor the lexical requirements of the words in the sentence. They must, for example, eliminate an analysis that treats an NP following a purely intransitive verb such as struggle as its direct object.

The present paper reexamines some often-cited evidence (Mitchell, 1987) about how lexical information, such as verb transitivity, is used in parsing. This evidence has been taken as a strong argument that sentence structure is created on the basis of general principles and not simply retrieved from memory as configurations prestored with lexical items. To our disappointment, we conclude that the evidence cannot be taken at face value and that other arguments must be developed to decide whether parsing is a matter of structure building or structure retrieval.

There is substantial agreement that such lexical subcategorization information (information about the possi-

The present research was supported by Research Grant HD 18708 and Training Grant MH 16745 to the University of Massachusetts. The research was begun while D.C.M. was visiting the University of Massachusetts as a Senior Fulbright Scholar with the support of grants from the Nuffield Foundation and the ESRC (R-0023-1596). The authors would like to thank Martin Corley, Lyn Frazier, and Shelia Kennison for their very helpful comments on an earlier version of this paper. Requests for reprints should be directed to B. C. Adams, Department of Psychology, Randolph-Macon Woman's College, Lynchburg, VA 24503-1256, or C. Clifton, Jr., Department of Psychology, University of Massachusetts, Amherst, MA 01003 (e-mail: cec@psych.umass.edu). ble phrasal complements of a verb or other word) is used quickly, within a period of $0.4-2 \mathrm{sec}$ of word processing (see Boland \& Tanenhaus, 1991; Boland, Tanenhaus, \& Garnsey, 1990; Ferreira \& Henderson, 1991; Frazier, 1989; Mitchell, 1989, 1994; Tanenhaus, Carlson, \& Trueswell, 1989; and Trueswell, Tanenhaus, \& Kello, 1993, for reviews). However, there is considerable disagreement about the precise mechanism by which subcategorization information is used. At one extreme are models that maintain that only major category information, such as noun or verb, and phrase structure rules are used in assembling the initial structure. Such models have been entertained by Frazier (1987a, 1989) and by Mitchell (1987, 1989). These models claim that detailed lexical information plays its role only after an initial structure is built, filtering out analyses that violate lexical constraints.

At the other extreme are "lexical guidance" theories, which hold that specific lexical information is the only source of syntactic structure. Ford, Bresnan, and Kaplan (1982) suggest that the lexical entry for each verb contains prestored information about the syntactic frames in which it can participate or enter, together with information about the relative salience of these frames. When the verb is encountered in a sentence, its preferred frame is retrieved and used as a partial syntactic structure to accommodate any complements or arguments. MacDonald, Pearlmutter, and Seidenberg (1994) provide a more recent version of such an account in their claim that "[w]ith X-bar structures [generic pieces of phrase structure associated with heads of phrases] in the lexicon, it is possible to treat the entire process of constructing a syntactic structure as a matter of connecting X-bar structures to each other in the appropriate syntactically required manner" (p. 683).

Less extreme lexical guidance theories exist, all of which permit lexical subcategorization information to affect the initial parse of a sentence without claiming that 
detailed lexical information stored with individual words is the only source of sentence structure (Abney, 1987, 1989; Boland \& Tanenhaus, 1991; Frazier, 1985, 1989, 1990; Gibson, 1990; Hemforth, Konieczny, Scheepers, \& Strube, 1994; Pritchett, 1988, 1992; Tanenhaus, Boland, Mauner, \& Carlson, 1993; Tanenhaus, Garnsey, \& Boland, 1990; Weinberg, 1995). Mitchell (1987) provided evidence against models claiming that initial syntactic analyses could not violate lexical subcategorization requirements and favoring models claiming that initial analyses reflected general grammatical principles. He examined the self-paced reading of sentences like those labeled $1 \mathrm{a}$ and $1 \mathrm{~b}$ below, which are presented in two regions, as indicated by the "/" mark. Ignoring subcategorization information for the moment, the widely discussed late-closure parsing principle (Frazier, 1987a) predicts that the postverbal NP "the doctor" will be taken as the object of the verb it follows. The principle states, "If grammatically permissible, attach new items into the clause or phrase currently being processed" (Frazier, 1987a). Since the verb phrase (VP) is being processed when the postverbal NP is read, the latter will be attached into the former and taken as its direct object.

1a. After the child had sneezed (during surgery) the doctor / prescribed a course of injections.

1b. After the child had visited (during surgery) the doctor/prescribed a course of injections.

If the doctor is attached as direct object of the intransitive verb sneeze, the resulting analysis will violate the verb's subcategorization requirements. Such an analysis should not be constructed if parsing is initially guided by the verb's subcategorization. However, if the analysis is made despite the subcategorization violation, it will have to be rejected. Such a process of constructing and then rejecting an analysis results in a "garden path" (Frazier \& Rayner, 1982) and should appear as disruption in reading.

Mitchell (1987) in fact found a disruption of some $700 \mathrm{msec}$ in reading the first segment when an intransitive verb (such as sneezed), as opposed to a potentially transitive verb (such as visited), was followed immediately by an NP in the same presentation region (compare 1a and lb). Disruption appeared in the next region when the verb was potentially transitive. Mitchell suggested that readers took the NP immediately following a verb as the direct object of the verb even when the verb did not permit a direct object. Since such an analysis violates lexical information, it would have to be rejected, disrupting reading. No disruption occurred when an adverbial phrase (e.g., during surgery) immediately followed the intransitive verb. Inserting an adverb between verb and NP blocked the analysis in which the NP is taken as object of an intransitive verb. The study apparently demonstrates that subcategorization fails to block an inappropriate reading, although the presence of an adverbial phrase between an intransitive verb and the NP succeeds. Thus, lexical information can be overlooked in a way in which phrase structural information cannot be, suggesting that the latter, but not the former, plays a necessary role in initially assigning structure to a sentence.

This interpretation of the disruption effect has been termed "filtering," since it claims that lexical information is used to filter syntactic structures that were created in violation of the information. The filtering interpretation of Mitchell's data is controversial. Most criticism has focused on the segmentation used in Mitchell's experimental task. It has been suggested that the division into presentation regions might cause readers to "treat the first fragment of the sentence as a complete phrase or clause," thus encouraging "an incorrect intransitive analysis of the verb" (Fodor, 1988, p. 137; see also Fodor, 1989, p. 166). Similarly, Boland and Tanenhaus (1991, p. 338) have argued that a segmentation break after the word "doctor" might bias readers in favor of postulating a clause boundary after this word. In each case, the cues to structure provided by segmentation would be in conflict with the linguistic cues from the sentence itself. On such accounts, the misparses demonstrated by Mitchell (1987) may be attributed not to the failure to make immediate use of lexical information, but to the misleading effects of artificial segmentation.

The primary purpose of the present experiment was to examine the simple form of the criticism that Mitchell's results depended upon the self-paced reading task he used. The experiment differed from Mitchell's in that the texts were presented with no breaks and eye movements were monitored during normal reading. If disruption is observed on the NP following a pure intransitive verb under these procedures, it cannot be attributed to some demand characteristic of the self-paced reading task.

In preliminary work, Adams, Clifton, and Mitchell (1992) used a control condition that differed from Mitchell's. Instead of disambiguating a sentence by inserting a prepositional phrase between a verb and a following NP, sentences were disambiguated by inserting a comma at this position (e.g., "After the dog struggled, the kindly old veterinarian took off the muzzle"). The comma is a signal that the initial clause is ended (overlooking such possibilities as conjoined verbs or VPs) and should block taking a postverbal NP as direct object. The comma presumably makes the minimal change in the sentence that serves the purpose of disambiguation. Adams et al. reported disruption while reading the NP immediately after an intransitive verb (with no intervening comma), supporting Mitchell's (1987) original observations.

However, it could be objected that the presence of a comma between two clauses is more felicitous than its absence, and that this difference in felicity could account for any disruption on an NP immediately following an intransitive verb. Because of that, we conducted the experiment reported below, using adverbial phrases rather than commas in the disambiguated control condition, as illustrated in Table 1. Each sentence began with a subordinate clause that contained either an intransitive or an 
Table 1

Examples of Sentence Used

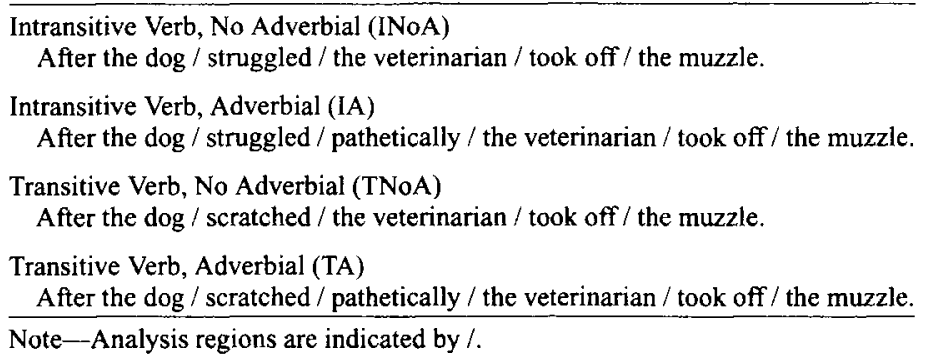

optionally transitive verb. An adverb or a prepositional phrase immediately followed the initial verb half the time. The presence of this adverb signaled that there were no more arguments of the verb, and thus that the verb was being used intransitively. The four conditions in which each sentence could appear will be called intransitive no adverb (INoA), intransitive adverb (IA), transitive no adverb (TNoA), and transitive adverb (TA). Each sentence continued with an NP that served as the subject of the main clause. In the INoA condition, the filtering claim predicts that the reader will take this NP as the direct object. To the extent that filtering is a time-consuming process, reading the NP will be disrupted as compared with the IA condition. The lexical guidance claim, on the other hand, predicts that the NP should be read equally well in the IA and NoA conditions, since in both cases it is taken initially as the subject of the main clause. Both claims predict that the NP will be read fast in the TNoA condition (as well as in the TA condition, apart from the fact that the NP in this condition must be taken to begin a new clause), but that the following disambiguating verb will be read slowly in the TNoA condition.

\section{METHOD}

\section{Materials and Design}

Twenty-four sets of 4 sentences were constructed, in four forms each as illustrated in Table 1. These 24 sentences were embedded in a list of 112 sentences total, in a variety of constructions. To ensure that subjects attended to the sentences, half of all sentences (including 12 of the 24 experimental sentences) were followed by simple two-choice questions.

\section{Subjects}

Thirty-six University of Massachusetts students were tested in individual 40-min sessions. Each was paid $\$ 5$ for participation.

\footnotetext{
Procedure

Sentences were presented using an 80-column VGA display, with approximately four characters per degree of visual angle. The experimental sentences were one or two lines long on the screen. The first line always contained the entire subordinate clause plus as much of the main clause as possible, at least through the disambiguating main verb of the sentence.

A subject's reading was measured with an SRI Generation V Eyetracker while his/her head was steadied by a bite bar. The subjects were told that they should read in a normal fashion and that they should press a button when they had read it to their satisfaction. Subjects were calibrated and then given a 4 -item practice list and the 112-item experimental list, each in an individually randomized order. Before each sentence, a brief calibration check was performed and the eyetracker was
}

recalibrated if necessary. During each sentence, an 80486 microcomputer interfaced with the eyetracker sampled the eye position each millisecond to determine when and where each fixation began and ended. Half the sentences were followed by a visually presented question, which the subject answered by pressing one of two buttons for "yes" or "no." The entire session took approximately $30 \mathrm{~min}$.

\section{RESULTS}

The sentences were divided into scoring regions, as illustrated in Table 1 . The sentence initial region, including the first NP, was Region 1, the intransitive or transitive verb was Region 2, the adverb (if present) was Region 3, the postverbal NP, Region 4, and the initial word or words (at least seven characters) of the disambiguating verb phrase, Region 5. All five regions were contained in the first line of the display. Table 2 presents the first fixation and first-pass and second-pass reading times for the verb region, the following NP, and the disambiguating region. The data for first- and second-pass reading times are shown in milliseconds/character rather than in unadjusted milliseconds simply to provide a rough comparability across the different regions (not to adjust for lengths within a region, since the regions of interest in the conditions being compared were identical). In each analysis, the four conditions formed by the combination of intransitive versus transitive verb and adverb versus no adverb were treated as a single four-level factor (to be referred to as "conditions," with levels INoA, IA, TNoA, and TA). Since one of the four conditions was predicted to be disrupted, planned comparisons were conducted comparing the predicted-long condition with the mean of the others, and testing for differences among the remaining three conditions. Post hoc Bonferroni $t$ tests were also conducted to make all possible comparisons among these four means, holding error rate for the entire experiment at .05 for both subjects and items analyses.

In the disambiguating verb phrase (Region 5), all theories predict disruption in the TNoA condition. It is the only condition in which the erroneous direct object analysis of the postverbal NP is presumably maintained into the final verb phrase. There was substantial evidence of garden-pathing in this condition. First fixation times differed significantly among the four conditions $\left[F_{1}(3,105)=\right.$ $6.15, M S_{\mathrm{e}}=1,781, p<.001 ; F_{2}(3,66), M S_{\mathrm{e}}=1,260, p<$ $.002]$. In the planned contrast, reading times for the TNoA condition were significantly longer than the mean read- 
Table 2

Measures of Eye Movements

\begin{tabular}{|c|c|c|c|c|}
\hline \multicolumn{5}{|c|}{ Measures of Eye Movements } \\
\hline \multirow[b]{2}{*}{ Condition } & \multicolumn{4}{|c|}{ Region } \\
\hline & 2 (verb) & 3 (adverb) & $4(\mathrm{NP})$ & 5 (disambiguation) \\
\hline \multicolumn{5}{|c|}{ First Fixation* } \\
\hline Intransitive, no adverbial & 284 & & 283 & 283 \\
\hline Intransitive, adverbial & 276 & 300 & 283 & 278 \\
\hline Transitive, no adverbial & 278 & & 278 & 306 \\
\hline Transitive, adverbial & 277 & 304 & 299 & 263 \\
\hline \multicolumn{5}{|c|}{ First-Pass Time $\dagger$} \\
\hline Intransitive, no adverbial & 40.6 & & 35.5 & 45.3 \\
\hline Intransitive, adverbial & 40.6 & 40.6 & 35.5 & 42.9 \\
\hline Transitive, no adverbial & 42.5 & & 34.1 & 50.7 \\
\hline Transitive, adverbial & 39.3 & 46.2 & 37.8 & 43.2 \\
\hline \multicolumn{5}{|c|}{ Second-Pass Time $\dagger$} \\
\hline Intransitive, no adverbial & 14.8 & & 5.6 & 4.6 \\
\hline Intransitive, adverbial & 15.6 & 7.41 & 3.3 & 4.9 \\
\hline Transitive, no adverbial & 21.2 & & 15.2 & 15.7 \\
\hline Transitive, adverbial & 15.0 & 8.85 & 3.1 & 6.0 \\
\hline
\end{tabular}

*In milliseconds. †In milliseconds per character.

ing times in the remaining conditions $\left[t_{1}(35)=3.35, p<\right.$ $\left..001 ; t_{2}(23)=2.76, p<.01\right]$, whereas the remaining conditions differed only marginally $\left[F_{1}(2,70)=2.45, .05<\right.$ $\left.p<.10 ; F_{2}(2,70)=3.14, .05<p<.10\right]$. The post hoc tests indicated that reading times were significantly longer for the TNoA condition than for any other condition aside from the INoA condition (although this difference was significant by a simple $t$ test). No other pairwise differences approached significance.

First-pass times also differed significantly among conditions $\left[F_{1}(3,105)=4.73, M S_{\mathrm{e}}=99.2, p<.01 ; F_{2}(3,66)=\right.$ $\left.4.28, M S_{\mathrm{e}}=57.27, p<.01\right]$. The planned contrast between TNoA and the other conditions was significant $\left[t_{1}(35)=\right.$ $\left.3.10, p<.002 ; t_{2}(23)=3.17, p<.005\right]$. The post hoc tests indicated that the only differences that were significant were the slower reading times for the TNoA condition than for the others (with, again, the difference between TNoA and INoA only approaching significance, using the Bonferroni criterion). Finally, second-pass times showed the same differences $\left[F_{1}(3,105)=9.82, M S_{\mathrm{e}}=\right.$ $\left.104, p<.001 ; F_{2}(3,66)=16.30, M S_{\mathrm{e}}=39.4, p<.001\right]$. This time, the Bonferroni-adjusted $t$ tests indicated that second-pass reading times were significantly longer in the TNoA condition than in any other, which did not differ.

The region before disambiguation, the NP after the initial verb, is where only the filtering hypothesis had predicted disruption in the INoA condition. No differences approached significance in first fixation or first pass (all $p$ values $>.15$ ). In particular, there was no significant initial disruption on the immediately postverbal NP in the INoA condition. However, there was a hint of slow firstpass reading time in the TA condition (slowing on an NP that followed a transitive verb + adverb). While the Bonferroni contrast between this condition and the TNoA condition was nonsignificant, a simple $t$ test indicated that the difference was significant at the .05 level. The difference, if real, is interesting. In conjunction with the absence of any difference for intransitive verbs, it suggests that a di- rect object may be expected after an optionally transitive verb and that the appearance of the adverbial is disruptive. Direct evidence for this suggestion is found in the reading times for the postverbal adverbial phrase. While first fixation times did not differ significantly between adverbs following transitive versus intransitive verbs, first-pass times were longer following transitives than following intransitives [46.2 vs. $40.6 \mathrm{msec} / \mathrm{char}$; $F_{1}(1,35)=4.34, p<$ $\left..05 ; F_{2}(1,22)=7.29, p<.02\right]$.

Finally, second-pass times in the postverbal NP did differ among conditions $\left[F_{1}(3,105)=15.73, M S_{\mathrm{e}}=75.0\right.$, $\left.p<.001 ; F_{2}(3,66)=8.78, M S_{\mathrm{e}}=90.5, p<.001\right]$. The planned comparisons were not conducted, since secondpass time reflects effects of later regions. The post hoc tests indicated significantly longer rereading in the TNoA condition than in any other condition, simply reflecting the garden-pathing observed in the analysis of the disambiguating verb region. No differences in any readingtime measure were significant in the region containing the verb.

\section{DISCUSSION}

No disruption was observed on an NP that immediately followed a pure intransitive verb when compared with the condition in which an adverbial intervened between the verb and the NP. The adverbial phrase grammatically prevents the NP from serving as direct object. Judging from the fact that no garden-pathing was observed on the disambiguating main verb when an adverb had been present following the initial subordinate verb, the adverb was effective in fulfilling its grammatical function.

However, unlike the comma in Adams et al. (1992), presence of the adverbial did not speed reading time on the NP following an intransitive verb. This pattern of results suggests that the absence of the comma in the ambiguous, intransitive initial verb condition of Adams et al. (and in all intransitive verb conditions of the present experiment) can be viewed as slowing reading time on the postverbal NP for no deeper reason than that a comma is expected at the clause break between an initial subordinate clause and a main clause.

Substantial disruption was observed on the disambiguating verb following the NP, but only in the condition in which a transitive initial verb had been followed immediately by an NP. This disruption can be viewed 
as reflecting the requirement to reanalyze the postverbal NP from direct object of the initial verb to subject of the main clause. The lack of disruption in the other conditions can then be viewed as reflecting the fact that either the intransitivity of the initial verb or the presence of the postverbal adverbial was sufficient to block the direct object analysis or to filter it before the disambiguating main clause verb was read.

The results of the present experiment prevent taking Mitchell's (1987) observations of disruption on an NP after an intransitive verb as evidence that the NP is initially taken as object of the verb. More generally, the new results discourage taking the earlier observations (including Adams et al., 1992) as evidence that initial syntactic analyses are made without reference to detailed lexical information such as verb subcategorization information. The observations of disruption in previous research must thus be attributed to other factors, presumably the absence of a comma at an obligatory clause break or the presentation of the verb and the following NP in a single display

The certain conclusion from the present data is that lexical subcategorization information is used very quickly in parsing, within the time that the postverbal NP is being read. It is tempting to make a stronger conclusion, that subcategorization information guided the initial analysis. The filtering hypothesis can be saved as an account of the present data only by claiming that filtering took place too quickly to be detected by the reading-time measures. If data about time to read NPs that follow transitive versus intransitive verbs were the only source of information about the parsing system, the lexical guidance interpretation would clearly be preferred over the filtering interpretation. ${ }^{1}$

However, an adequate theory of human sentence parsing must take into account more than the results of a single experimental paradigm. There are other reasons to continue to entertain the filtering hypothesis, even at the cost of claiming that it has no observable consequences in the experimental situation used in the present experiment.

One reason comes from evidence about the parsing of head-final languages (e.g., Frazier, 1987b, 1989) such as Japanese or Dutch. This evidence shows that projecting structure from verbs and other heads of phrases cannot be the only way in which parsing can be done. Taken literally, the claim that syntactic structure is projected via X-bar structures from the head of a phrase (MacDonald et al., 1994) predicts that structure will not be built in a Dutch subordinate clause or a Japanese sentence until its last word, its head verb. This claim must, at the very least, be supplemented by other processes for creating syntactic structure, possibly including the building of structure following phrase-structure rules. In this case, the filtering hypothesis would be one straightforward way of coordinating the use of phrase structure and lexical information.

Another reason to entertain the filtering hypothesis comes from the apparent ease of understanding such constructions as "sneezed a sneeze" or even "sneezed the napkin off the table." A parser (such as that in Ford et al., 1982, but probably not MacDonald et al., 1994) that uses available subcategorization information to place inviolable constraints against objects of intransitive verbs would have difficulty in accounting for these constructions.

A third reason not to discard the filtering hypothesis on the basis of the present data comes from one aspect of Mitchell's (1987) data. Recall that the presence of the adverb between an intransitive verb and an NP eliminated the disruption of reading the NP, even when verb + adverb + NP were in a single presentation region. The parser apparently treated the adverb as categorical information that the NP could not be the direct object of the verb. Even if one accepts the argument that Mitchell's observations with intransitive verbs resulted from demands placed by the segmentation he used, one has to acknowledge that these segmentation demands could overcome verb subcategorization information but not the phrase-structural information provided by the adverb. This observation is inconsistent with a model in which lexical information associated with verbs is the sole source of syntactic structure.

It seems best not to conclude that filtering models are wrong, but simply that they receive no support in the present data and that the apparent support they received in Mitchell (1987) is open to question. We suggest that the most reasonable course of action would be to develop models that can simultaneously account for the details of experimental data and explain how readers and listeners can build syntactic structures even when the structures cannot plausibly or logically be projected from heads of phrases (e.g., arguments in head-final languages, or adjunct phrases generally). We continue to think that it will be worthwhile to explore parsing models in which general grammatical principles are used in coordination with lexical information (including models in which multiple analyses are constructed on the basis of general principles and then filtered using lexical information, as did Stevenson, 1993), rather than concluding that lexical structure rigidly determines syntactic analysis.

\section{REFERENCES}

ABNEY, S. (1987). Licensing and parsing. In J. McDonough \& B. Plunkett (Eds.), Proceedings of the North Eastern Linguistics Society 17 (pp. 1-15). Amherst: University of Massachusetts, Graduate Linguistics Student Association.

ABNEY, S. (1989). A computational model of human parsing. Journal of Psycholinguistic Research, 18, 129-144.

Adams, B. C., Clifton, C. E., JR., \& Mitchell, D. C. (1992, November). Syntactic guidance in sentence processing. Poster presented at the 33rd annual meeting of the Psychonomic Society, St. Louis.

Boland, J., \& TANenhaus, M. K. (1991). The role of lexical representations in sentence processing. In G. B. Simpson (Ed.), Understanding word and sentence (pp. 331-366). Amsterdam: Elsevier, NorthHolland.

Boland, J. E., Tanenhaus, M. K., \& Garnsey, S. M. (1990). Evidence for the immediate use of verb control information in sentence processing. Journal of Memory \& Language, 29, 413-432.

FERREIRA, F., \& HENDERSON, J. M. (1991). Recovery from misanalyses of garden-path sentences. Journal of Memory \& Language, 30, 725-745.

FODOR, J. D. (1988). On modularity in grammar. Journal of Psycholinguistic Research, 17, 125-168.

FoDOR, J. D. (1989). Empty categories in sentence processing. Language \& Cognitive Processes, 4, SI155-SI210.

Ford, M., BRESnAN, J., \& Kaplan, R. (1982). A competence-based theory of syntactic closure. In J. Bresnan (Ed.), The mental representation of grammatical relations (pp. 727-796). Cambridge, MA: MIT Press.

FraZIER, L. (1985). Modularity and the representational hypothesis. In Proceedings of the North Eastern Linguistics Society 12 (pp. 131144). Amherst: University of Massachusetts, Graduate Linguistics Student Association.

Frazier, L. (1987a). Sentence processing: A tutorial review. In M. Coltheart (Ed.), Attention and performance XII (pp. 559-586). Hillsdale, $\mathrm{NJ}$ : Erlbaum.

Frazier, L. (1987b). Syntactic processing: Evidence from Dutch. Natural Language \& Linguistic Theory, 5, 519-559.

FRAZIER, L. (1989). Against lexical generation of syntax. In W. MarslenWilson (Ed.), Lexical representation and process (pp. 505-528). Cambridge, MA: MIT Press.

FrAZIER, L. (1990). Exploring the architecture of the language system. In G. Altmann (Ed.), Cognitive models of speech processing: $P_{s y-}$ cholinguistic and computational perspectives (pp. 409-433). Cambridge, MA: MIT Press.

FrAZIER, L., \& RAYNER, K. (1982). Making and correcting errors during sentence comprehension: Eye movements in the analysis of structurally ambiguous sentences. Cognitive Psychology, 14, 178-210.

Gibson, E. (1990). Recency preference and garden-path effects. In Proceedings of the 12th Annual Conference of the Cognitive Science Society (pp. 372-379). Hillsdale, NJ: Erlbaum.

Hemforth, B., Konieczny, L., Scheepers, C., \& Strube, G. (Eds.) (1994). First analysis, reanalysis, and repair. Freiburg, Germany: Albert-Ludwigs-Universität Freiburg, Institut für Informatik und Gesellschaft.

MacDonald, M. C., Pearlmutter, N. J., \& Seidenberg, M. S (1994). Lexical nature of syntactic ambiguity resolution. Pyscholog. ical Review, 101, 676-703.

MrTCHELL, D. C. (1987). Lexical guidance in human parsing: Locus and processing characteristics. In M. Coltheart (Ed.), Attention and performance XII (pp. 601-618). Hillsdale, NJ: Erlbaum. 
Mitchell, D. C. (1989). Verb-guidance and other lexical effects in parsing. Language \& Cognitive Processes, 4, SI123-SI1 54.

MrTCHELl, D. C. (1994). Sentence parsing. In M. A. Gernsbacher (Ed.), Handbook of psycholinguistics (pp. 375-409). New York: Academic Press.

PritchetT, B. L. (1988). Garden path phenomena and the grammatical basis of language processing. Language, 64, 539-576.

PrITCHETT, B. L. (1992). Grammatical competence and parsing performance. Chicago: University of Chicago Press.

STEVENSON, S. (1993, June). A competition-based explanation of syntactic attachment preferences and garden path phenomena. In Proceedings of the 31st Annual Meeting of the Association of Computational Linguistics (pp. 266-273). Columbus, $\mathrm{OH}$ : Association for Computational Linguistics.

Tanenhaus, M. K., Boland, J. E., Mauner, G., \& Carlson, G. N. (1993). More on combinatory lexical information: Thematic structure in parsing and interpretation. In G. Altmann (Ed.), Cognitive models of speech and processing: Vol. 2. Psycholinguistic and computational perspectives (pp. 297-319). Cambridge, MA: MIT Press.

Tanenhaus, M. K., Carlson, G., \& Trueswell, J. C. (1989). The role of thematic structures in interpretation and parsing. Language \& Cognitive Processes, 4, SI211-SI234.
Tanenhaus, M. K., Garnsey, S., \& Boland, J. (1990). Combinatory lexical information and language comprehension. In G. Altmann (Ed.), Cognitive models of speech processing (pp. 383-408). Cambridge, MA: MIT Press.

Trueswell, J. C., Tanenhaus, M. K., \& Kello, C. (1993). Verbspecific constraints in sentence processing: Separating effects of lexical preference from garden-paths. Journal of Experimental Psychology: Learning, Memory, \& Cognition, 19, 528-553.

WADE, M. M., \& ADAMS, B. C. (1998). The role of verb transitivity information in sentence processing. Unpublished manuscript, University of Virginia.

WEINBERG, A. (1995). Licensing constraints and the theory of language processing. In R. Mazuka \& N. Nagai (Eds.), Japanese sentence processing (pp. 235-256). Hillsdale, NJ: Erlbaum.

\section{NOTE}

1. Wade and Adams (1998) present two word-by-word self-paced reading experiments that examine constructions very similar to those studied here and yield data very similar to those we report. They concentrate on modeling these data and argue that they support a lexical guidance model.

\section{APPENDIX A}

Materials

After the dog \$struggled|scratched\$ (pathetically) the vet took off the muzzle.

As the ship \$drifted|sailed\$ (away) the waters remained blue and calm.

Though the young swimmer \$sulked/phoned\$ (frequently) the coach refused to permit him to join the team.

After the pilgrims \$prayedibegged\$ (at length) the Indians lit the peace pipe.

While the baby $\$$ slept|kicked $\$$ (in the crib) the babysitter took a nap.

While the crowd \$gaped|cheered\$ (in astonishment) the magician sawed the woman in half.

After the students \$gossiped|gobbled\$ (rudely) the desserts were taken away by the waiter.

Shortly after the gangster \$died|shot\$ (unnecessarily) his wife burst into hysterics.

After the woman \$emerged|dressed\$ (with a flair) her children thought she looked lovely.

Although her baby daughter \$squirmed|clutched\$ (feverishly) the woman stayed until the end of the program.

When the teacher \$talked|taught\$ (in a monotone) the visitors lost interest in the lesson.

After the host \$disappeared|interrupted\$ (impolitely) the conversation became interesting and educational.
Although the audience \$yawned|booed\$ (collectively) the comedian continued telling very bad jokes.

After the patient \$coughed|probed\$ (feebly) the nurse told her that the doctor would be in shortly.

After the soldier \$fainted|saluted\$ (at attention) the doctor demanded the end to the military drill.

While the new guard \$dozed|bluffed\$ (irresponsibly) the thieves filled their bags with money.

After the lifeguard \$smiled|visited $\$$ (politely) the swimmers jumped into the pond.

As the teenager \$daydreamed|contemplated\$ (drowsily) the teacher asked him a direct question.

After the rooster \$crowed|awoke\$ (raucously) the farmer went to the hen house to gather eggs.

While the woman \$gardened|decorated\$ (diligently) the pot boiled over on the stove.

While the prisoners $\$$ fasted/heckled $\$$ (in their cells) the guards refused to discuss their grievances.

While the bachelor \$mused|smoked $\$$ (contentedly) his pipe fell to the floor and started a fire.

When the customer \$complainediinterrupted\$ (forcefully) the manager changed the wording of the advertisement.

As long as the king \$prevailed|governed\$ (successfully) his subjects hoped he would have a son.

Note-Alternatives are enclosed by $\$$... . . . \$. 